\title{
Chamber musicians' acoustic impressions of auditorium stages: Relation to spatial distribution of early reflections and other parameters
}

\author{
Lilyan Panton, ${ }^{1, a)}$ Manuj Yadav, ${ }^{2}$ Densil Cabrera, ${ }^{2}$ and Damien Holloway ${ }^{1}$ \\ ${ }^{1}$ School of Engineering, University of Tasmania, Hobart, Tasmania, Australia \\ ${ }^{2}$ School of Architecture, Design and Planning, University of Sydney, New South Wales, Australia
}

(Received 17 September 2018; revised 23 May 2019; accepted 28 May 2019; published online 26 June 2019)

\begin{abstract}
Characterizing stage acoustics using objective parameters has seen some recent resurgence-several studies have noted the importance of the directionality of early stage reflections to musicians, which is not adequately represented using existing omnidirectional stage-support parameters. This study examines the subjective impressions of 19 chamber musicians against omnidirectional [reverberation time, early and late support $\left(S T_{\text {Early }}, S T_{\text {Late }}\right)$, etc.], and proposed spatially-defined parameters (TH and $T S$ ), along with simple ratios of stage dimensions derived from measurements on eight purpose-built stages. $T H$ is a ratio of early energy from "above" to that from the "horizontal," while $T S$ relates energy from above to that from the "sides" of the stage. Robust mixed-effects analyses showed that the musicians' overall acoustic impression ratings are predicted (i) by $T H$ within a linear model; (ii) by $T H \times S T_{\text {Early, }} T H \times S T_{\text {Late }}$, and $T S \times S T_{\text {Early, }} T S \times S T_{\text {Late }}$; (iii) by $S T_{\text {Early }}, S T_{\text {Late }}$ each within parabolic models; and (iv) by several architectural parameters' linear and parabolic models. These findings reinforce recent studies of spatially-defined parameters to more fully account for the subtleties of onstage sound fields. Some simple design recommendations are presented, although future studies are needed to confirm these findings/recommendations for a wider range of auditorium stages. (C) 2019 Acoustical Society of America. https://doi.org/10.1121/1.5111748
\end{abstract}

$[\mathrm{BFGK}]$

Pages: $3715-3726$

\section{INTRODUCTION}

Past studies ${ }^{1-4}$ of stage acoustics for musicians have aimed to define measurable acoustic parameters that can indicate the qualities of on-stage acoustics for performing musicians. Marshall et al. ${ }^{1}$ studied a string trio playing in a simulated acoustic environment and concluded that early reflections arriving within $17-35 \mathrm{~ms}$ after the direct sound improve ensemble. Barron ${ }^{2}$ studied musicians' impressions in a hall with an adaptable stage enclosure and found a possible preference for a close ceiling reflection. Others ${ }^{3-7}$ have proposed acoustic parameters designed to be measured on stage. These stage acoustical parameters are usually either energy ratios of parts of an impulse response, or of a pair of impulse responses, and may be stated in the general form

$$
X=10 \log _{10} \frac{\int_{t_{3}}^{t_{4}} p_{\mathrm{A}}^{2}(t) \cdot \mathrm{d} t}{\int_{t_{1}}^{t_{2}} p_{\mathrm{B}}^{2}(t) \cdot \mathrm{d} t},
$$

where $p_{\mathrm{A}}$ and $p_{\mathrm{B}}$ are the pressures at receivers located at positions $\mathrm{A}$ and $\mathrm{B}$, respectively, and $t_{1}, t_{2}, t_{3}$, and $t_{4}$ are integration time limits. Table I presents a summary of parameters defined in the form of Eq. (1), along with the relevant integration times, source-receiver distances, and possible subjective use. Although the parameters reverberation time $\left(T_{30}\right)$ and early

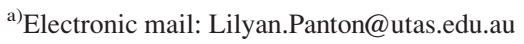

decay time (EDT) have been used in stage acoustics investigations, they do not use the form of Eq. (1) and so are not included in Table I.

Gade $^{3,8}$ proposed the commonly used Stage Support (ST) measures to assess ensemble conditions and quality of late reflections on stage, as well as early ensemble level (EEL) and stage clarity $(C S)$. Gade $^{3}$ tested their subjective relevance through three experiments involving surveying symphony orchestra musicians and on-stage measurements. The first and third studies showed large correlations between $S T_{\text {Early }}$ and subjective responses, whereas the second did not. EEL also did not correlate with subjective ratings ${ }^{3}$ and has since been abandoned in favor of $S T_{\text {Early. }}$ Similarly, $S T_{\text {Late }}$ (Ref. 8) replaced $C S$ (Ref. 3) as a stage parameter for late energy on stage. More recently, $S T_{\text {Early }}$ and $S T_{\text {Late }}$ have been included in ISO 3382-1. ${ }^{9}$

Dammerud ${ }^{4}$ investigated the support measures, along with other omnidirectional parameters (including variations on the sound strength parameter $G$ defined in Ref. 9) and carefullydefined architectural measures, in a comprehensive study of stage acoustics for symphony orchestras. Dammerud's first survey included 22 halls and his second survey focused on eight halls, and results were also compared to surveying by Cederlö ${ }^{10}$ with symphony orchestras in five halls. Based on his findings, Dammerud was critical of the use of $S T_{\text {Early }}$ for characterizing stage acoustics for musicians in symphony orchestras. Dammerud discussed that, while the late reverberation on stage was important, as characterized by $T_{30}$ and $S T_{\text {Late }}$, the relevance of $S T_{\text {Early }}$ was not well-established. Dammerud ${ }^{4}$ also did not find improved subjective relevance for the modified versions of $G$. However, Dammerud found that some stage 
TABLE I. Examples of values used in Eq. (1) $X=10 \log _{10}\left[\int_{t_{3}}^{t_{4}} p_{\mathrm{A}}^{2}(t) \cdot \mathrm{d} t / \int_{t_{1}}^{t_{2}} p_{\mathrm{B}}^{2}(t) \cdot \mathrm{d} t\right]$ Receiver locations " $>1 \mathrm{~m}$ " indicates cases where source-receiver placement across-stage was typically for some distance greater than $1 \mathrm{~m}$. Note that further variants exist in the literature.

\begin{tabular}{|c|c|c|c|c|c|c|c|}
\hline Parameter & $t_{1}(\mathrm{~ms})$ & $t_{2}(\mathrm{~ms})$ & $t_{3}(\mathrm{~ms})$ & $t_{4}(\mathrm{~ms})$ & $\begin{array}{l}\text { Receiver location } \\
\text { for } p_{A}\end{array}$ & $\begin{array}{l}\text { Receiver location } \\
\text { for } p_{B}\end{array}$ & Possible use \\
\hline$S T_{\text {Early }}\left(S T_{1}\right)$ & 0 & 10 & 20 & 100 & $1 \mathrm{~m}$ & $1 \mathrm{~m}$ & Ensemble conditions (Refs. 3, 8, and 9) \\
\hline$S T_{\text {Late }}$ & 0 & 10 & 100 & 1000 & $1 \mathrm{~m}$ & $1 \mathrm{~m}$ & Reverberance (Refs. 8 and 9) \\
\hline$E E L$ & 0 & 10 & 0 & 80 & $>1 \mathrm{~m}$ & $1 \mathrm{~m}$ & Ensemble conditions (Ref. 3) \\
\hline$C_{80}(C S)$ & 80 & $\infty$ & 0 & 80 & $1 \mathrm{~m}$ & $1 \mathrm{~m}$ & Reverberance (Ref. 3) \\
\hline$G_{\text {Early }}$ & 0 & $\infty$ & 0 & 80 & $1 \mathrm{~m}$, or $6-13 \mathrm{~m}$ & $10 \mathrm{~m}$ free field & Alternative to $S T_{\text {Early }}$ (Ref. 4) \\
\hline$G_{\text {Late }}$ & 0 & $\infty$ & 80 & $\infty$ & $1 \mathrm{~m}$, or $6-13 \mathrm{~m}$ & $10 \mathrm{~m}$ free field & Alternative to $S T_{\text {Late }}$ (Ref. 4) \\
\hline$G_{7-50}$ & 0 & $\infty$ & 7 & 50 & $1 \mathrm{~m}$, or $6-13 \mathrm{~m}$ & $10 \mathrm{~m}$ free field & $\begin{array}{l}\text { Response of stage, excluding floor } \\
\text { reflection (Ref. 4) }\end{array}$ \\
\hline$L Q_{7-40}$ & 40 & $\infty$ & 7 & 40 & $>1 \mathrm{~m}$ & $>1 \mathrm{~m}$ & Acoustic conditions for a conductor (Ref. 5) \\
\hline$L Q_{7-40}$ Tор $^{\mathrm{a}}$ & 40 & $\infty$ & 7 & 40 & $>1 \mathrm{~m}$ & $>1 \mathrm{~m}$ & Directional distribution (Ref. 6) \\
\hline$L Q_{7-40 \text { Sides }}{ }^{a}$ & 40 & $\infty$ & 7 & 40 & $>1 \mathrm{~m}$ & $>1 \mathrm{~m}$ & Directional distribution (Ref. 6) \\
\hline$T S$ & $t_{l}=12-15$ & $t_{u}=50,100^{\mathrm{b}}$ & $t_{l}=12-15$ & $t_{u}=50,100^{\mathrm{b}}$ & $1 \mathrm{~m}$ top & $1 \mathrm{~m}$ left and right & Directional distribution (Ref. 7) \\
\hline$T H$ & $t_{l}=12-15$ & $t_{u}=50$ or $100^{\mathrm{b}}$ & $t_{l}=12-15$ & $t_{u}=50$ or $100^{\mathrm{b}}$ & $1 \mathrm{~m}$ top & $1 \mathrm{~m} \mathrm{left}$, right and back & Directional distribution \\
\hline
\end{tabular}

${ }^{\text {a }}$ The parameter of interest $L Q_{7-40} \mathrm{Top} / \mathrm{Sides}$ is found as a ratio (i.e., decibel difference) of the two parameters given.

${ }^{\mathrm{b}} \mathrm{See}$ Sec. II B and Fig. 4 for details about the choice between two upper time limits.

dimensions and ratios of stage dimensions correlated with musician preferences. A preference for narrow and high stage enclosures was reported, which were possibly beneficial for symphony orchestras due to minimization of masking (particularly from loud brass instruments), minimizing delays across stage, and allowing players to hear the room's acoustic response. $^{4}$

Since early work by Gade, ${ }^{11}$ the design of effective questionnaires to gather subjective preferences from musicians on stage has also seen some development. ${ }^{12-17}$ Based on interviews with classical musicians, Gade ${ }^{11}$ lists "reverberance," "support," "timbre," "dynamics," "hearing each other," and "time delay" as important acoustical qualities. Ueno et al. ${ }^{12}$ interviewed 14 professional chamber musicians and found hearing each other and "making harmony" (i.e., blending) were consistently described as essential. Others have proposed more aspects to be included on questionnaires, such as "hearing self," "ease of ensemble," "clarity," "balance," "warmth," and a separate "overall acoustic impression" (OAI) scale. ${ }^{13-15}$ Dammerud ${ }^{15}$ also suggested that certain background information should be collected, such as musician's instrument, playing experience, and stage position. Gade ${ }^{16}$ reiterated a comprehensive list of important acoustic attributes, while stating that the list may be reduced to avoid "fatigue" and "confusion." Gade ${ }^{16}$ also emphasized the importance of surveying musicians shortly after a playing experience to obtain reliable responses. Kalkandjiev and Weinzierl ${ }^{17}$ proposed a "Stage Acoustic Quality Inventory" to be used as a questionnaire for musicians and found 17 separate items using a confirmatory factor analysis to describe room acoustic properties (grouped into five dimensions). This number of factors is far higher than in previous work, where not more than two factors were found from questionnaires with orchestral musicians. ${ }^{3,4}$

Besides the use of the more established omnidirectional parameters listed in ISO 3382-1, recent studies have also examined the directionality of on-stage sound fields, ${ }^{6,7,18-20}$ including the use of microphone arrays to capture highresolution spatial information. In a series of studies, Ueno et $a l .{ }^{18,21,22}$ developed a method for measuring on-stage auditorium impulse responses using a six-cardioid microphone system (with microphones mutually orientated at $90^{\circ}$ ) primarily for real-time, spatially realistic, and measurementbased auralizations of the stage environments in the laboratory. Directional versions of stage support measurements were investigated by Cabrera et al. ${ }^{19}$ using a first-order Ambisonic microphone to demonstrate the spatial acoustic effect of a theatrical stage set. Higher-order Ambisonic microphones are increasingly being used for auditorium acoustics measurements, but mostly without a particular focus on the stage. ${ }^{23,24}$ Guthrie $^{6}$ used a second order Ambisonic microphone for measurements on actual stages before recreating these sound fields synthetically. Guthrie then examined acoustic parameters defined spatially, as well as temporally, and found $L Q_{7-40} \mathrm{Top} / \mathrm{Sides}$ (a ratio of on-stage sound energy from above relative to from the sides) correlated with musicians' preferences. This concurs with earlier work by Domínguez, ${ }^{20}$ who found soloists playing in six simulated acoustic environments preferred close lateral reflections and far ceiling reflections. Dammerud ${ }^{4}$ and Guthrie $^{6}$ also used ray-tracing to study the spatial distribution of sound on stages. Dammerud included a symphony orchestra on stage, whereas Guthrie used unoccupied stages. Dammerud concluded that providing unobstructed reflections from surfaces close to the orchestra at the sides was most beneficial. Guthrie explored findings about $L Q_{7-40} \mathrm{Top} / \mathrm{Sides}$ by examining variations on a simple stage enclosure, concluding that high ceilings and stage walls close enough to give early reflections within $30 \mathrm{~ms}$ of the direct sound consistently provided "optimum" conditions, based on earlier auralization work. ${ }^{6}$

In preliminary work exploring spatial characteristics of sound fields on stage using higher-order microphone arrays, Panton $e t a l .7$ reported a relationship between chamber musicians' assessments, and a spatially defined parameter $T S_{20-50}$, 
which is the ratio of energy from "top" to that from the sides on stage arriving over $20-50 \mathrm{~ms}$. However, this work had several acknowledged limitations, and had identified future areas of improvement. This included considering back wall reflections, i.e., incorporating the "back" region into a spatial ratio, similar to the top-side spatial ratio $\left(T S_{20-50}\right)^{7}$ and considering the usefulness of architectural measures, such as stage dimensions in Dammerud. ${ }^{4}$ Statistical analysis in the paper by Panton et $\mathrm{al}^{7}{ }^{7}$ was also limited to regression using median values of the musicians' rating of the OAI per hall. Such an analysis ignores the repeated-measures design of the study, wherein the same musicians are rating several halls. As such, the analysis violated the assumption of independent errors (i.e., homoscedasticity) in parametric statistical inference, which can bias the standard errors of the model parameters, in turn affecting significance tests (such as $t$-tests), calculation of confidence intervals (CIs), and reducing the overall statistical power. ${ }^{25}$

Building on previous studies of stage acoustics for musicians, the main aims of the present study are as follows:

(a) to determine the relationship between existing omnidirectional stage acoustic parameters, and chamber musicians' subjective preferences: In the current paper, as in earlier studies, ${ }^{3,4,12}$ the relevance of early reflections on stage (as characterized by EDT on stage, $S T_{\text {Early }}, G_{\text {Early }}$ ) to musicians is investigated, as well as the relevance of late reflections on stage (as characterized by $T_{30}, S T_{\text {Late }}$, and $G_{\text {Late }}$ );

(b) to examine ways in which spatial analysis can be used to characterize onstage sound fields and subsequently determine the relationship between these spatiallydefined acoustic parameters, and the subjective preferences of chamber musicians: As noted above, several recent studies have proposed that the spatial distribution of reflection on stage is important. ${ }^{4,6,7,19}$ In the current study, the ratio of reflections from above to (i) those from the sides, and (ii) those from the horizontal directions, i.e., sides and back of stage, are considered. Furthermore, the importance of simple architectural ratios of the stage is explored.

\section{METHODS}

\section{A. Auditoria, questionnaire, and musicians}

A questionnaire about the experience of playing in eight purpose-built auditoria was administered to four professional Australian and international touring chamber music ensembles. The eight halls in alphabetical order are: Adelaide Town Hall (AH), City Recital Hall Angel Place (AP, Sydney), Hamer Hall (HH, Melbourne), Llewellyn Concert Hall (LH, Canberra), Perth Concert Hall (PH), Queensland Performing Arts Centre Concert Hall (QC, Brisbane), Sydney Opera House Concert Hall (SO), and Wollongong Town Hall (WH). The questionnaire asked musicians to rate auditoria on the following subjective scales: Overall Acoustic Impression, Hearing Self, Support, Ensemble, Reverberance, Clarity, Warmth, Timbre, Communication with the main auditorium, Echoes, and Visual Impression. The questionnaire, printed on A4 paper, included a continuous scale of $10 \mathrm{~cm}$ in length for each scale. A copy of the questionnaire is included in supplementary material. $^{26}$ The questionnaire booklet also included a section where musicians were asked to provide some background information, including instrument, whether playing as a section principal, and years of playing experience. Each musician completed a separate questionnaire for each auditorium on the tour, and the questionnaires completed by each musician were linked. This differed from the survey design used by Gade, ${ }^{3}$ Dammerud, ${ }^{4}$ and Cederlöf, ${ }^{9}$ where individual musicians were not given an identifier and, hence, individual musician trends could not be studied.

The four participating ensembles included one large Australian ensemble: The Australian Chamber Orchestra (ACO), 22 players; and three small ensembles (not named to preserve respondent anonymity) from Europe and North America: 2-4 players, each. In all cases, the questionnaires were completed in conjunction with relevant tours of each ensemble so that the musicians would have played the same musical works recently in each assessed auditorium. The ACO plays regularly in the eight halls of the current study. On the surveyed tour in June 2015 they performed 16th and 17th century repertoire involving strings with woodwind and harpsichord, and included keyboard and violin solos (compositions by Lawes, Purcell, Bach, and Haydn). The response rate was high: 15 of 22 ACO musicians $(68 \%)$ completed questionnaires. The three chamber ensembles completed questionnaires during various tours throughout 2016 with response rates between $33 \%$ and $50 \%$ (i.e., 1-2 respondents per ensemble). These chamber ensembles played in four of the same halls as the ACO (AP, LH, PH, and $\mathrm{AH}$ ), and, unlike the ACO, were not familiar with the auditoria. Preliminary analysis ${ }^{27}$ showed that despite the smaller sizes of these three ensembles, subjective ratings were very similar to those of the ACO musicians; hence questionnaire responses were combined for the halls in which these groups performed. The combined dataset had 4 musicians from three smaller ensembles (2,1,1 responses per ensemble) and 15 musicians from the ACO, resulting in a total of 19 musicians. The average number of professional playing years for musicians was $16.1 \pm$ $7.6 \mathrm{yr}$ (standard deviation). The surveyed musicians played instruments including violin, viola, cello, oboe, horn, double bass, and piano.

Figure 1 shows a summary of subjective data for all 11 subjective scales, in all eight halls. Preliminary analyses ${ }^{27}$ showed a high correlation between the OAI scale and other subjective criteria, particularly for support, timbre, ensemble, all with Spearman's $r>0.68$. However, correlation between OAI and reverberance was lower $(r=0.50)$, and musicians gave ratings close to the optimum of 5 (out of 10) for reverberance in all halls.

\section{B. Acoustic stage measurements}

Acoustic stage measurements were conducted in the eight auditoria subjectively assessed by ACO and chamber ensemble musicians (Sec. II A), using an omnidirectional source (Brüel \& Kjær type 4295 with power amplifier type 2734) and a 32-channel spherical microphone array (Eigenmike $32^{\mathrm{TM}}$ ). In four halls, in addition to the Eigenmike, an omnidirectional receiver was used (Brüel \& Kjær type 4190). Computer 


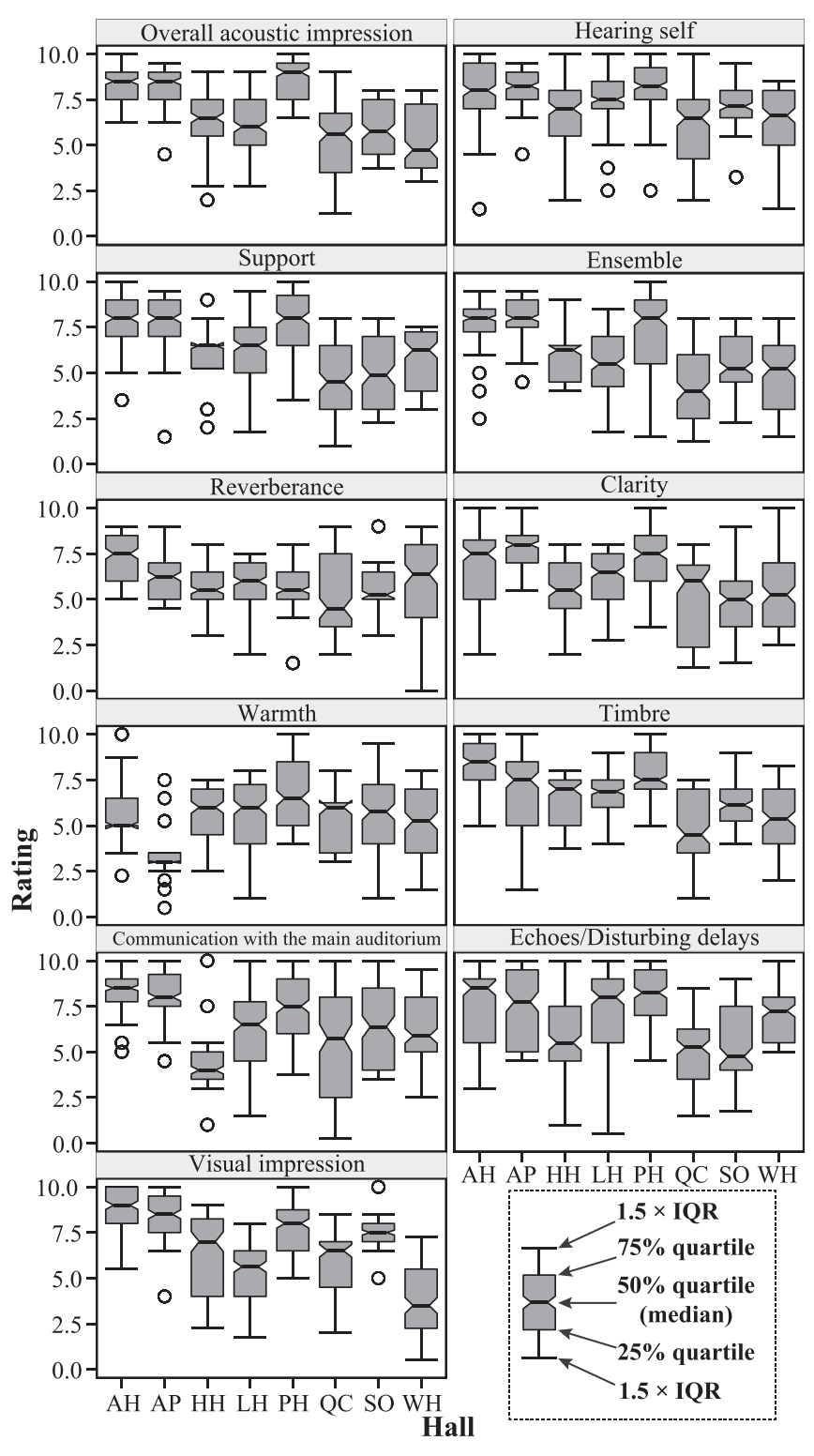

FIG. 1. Box plots for musicians' ratings of questionnaire items in eight halls. Data beyond $1.5 \times \mathrm{IQR}$ (inter-quartile range) are plotted individually.

software and an audio interface were used: AARAE (release $6)^{28}$ and Fireface UCX interface.

Source and receiver heights of $1.5 \mathrm{~m}$ above the stage floor were used for all measurements because ACO musicians mostly play standing. Measurements were completed on unoccupied stages. The on-stage measurement positions are shown in Fig. 2. The measurements consisted of both $1 \mathrm{~m}$ separation (support measurements), at four locations around each source position shown in Fig. 2, and across-stage measurements between all combinations of the 4 source locations, resulting in a total of 12 across-stage measurements.

\section{Acoustic and architectural parameters}

The omnidirectional acoustic parameters derived from the stage measurements (Table II) were the support measures: $S T_{\text {Early }}$ and $S T_{\text {Late }}$; the equivalent $G$ stage parameters: $G_{\text {Early }}$ and $G_{\text {Late }}$, respectively; reverberation time: $T_{30}$, measured for both the stalls and the stage; and EDT. The support
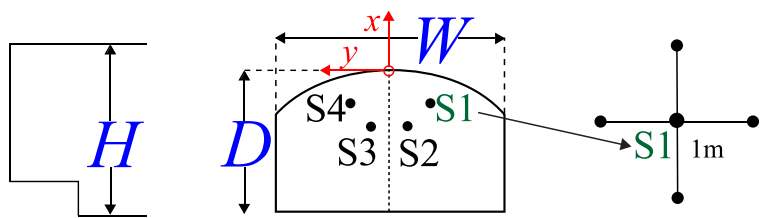

FIG. 2. (Color online) The on-stage measurement locations for ACO auditoria. The coordinate system's origin is located at the center front of the stage and sources coordinates are S1 $(-1.5,-3), \mathrm{S} 2(-4,-2), \mathrm{S} 3(-4,2)$, and S4 $(-1.5,3)$. Dimensions are in meters. Receivers had the same locations for across-stage measurements. For $1 \mathrm{~m}$ measurements, receiver positions were $(1,0),(0,1),(-1,0)$, and $(0,-1)$ relative to the four source positions (as shown for $\mathrm{S} 1)$. Also shown are simple architectural measures $(D, W$, and $H)$ used to define stage dimensions shown on a generic stage in plan-view and long-view. $D$ is depth from center front of stage to back wall of stage enclosure. $W$ is width of reflecting surfaces at side of stage. $H$ is the height to reflecting surfaces above the front section of stage; where there were large reflectors, the height from the front of the stage to these surfaces was used.

measures were found as the arithmetic average of 16 onstage measurements with $1 \mathrm{~m}$ source-receiver distance, and as the arithmetic average of $250-2000 \mathrm{~Hz}$ octave-bands, in accordance with ISO 3382-1. ${ }^{9} G_{\text {Early }}$ and $G_{\text {Late }}$ were found as the power-average of all across-stage measurements (source receiver distances $>2.7 \mathrm{~m}$ ) for $500-2000 \mathrm{~Hz}$ octavebands, as used by Dammerud. ${ }^{4} T_{30}$ on stage was found as the average of all across-stage measurements (source-receiver distance between 2.7 and $6 \mathrm{~m}$ ) and the average of 500 to $1000 \mathrm{~Hz}$ octave-bands. EDT on stage was found in the same manner. For comparison, " $T_{30}$ stalls" is also shown in Table II, which is the average of measurements with receiver positioned at six or more seats in the stalls and the on-stage source located at $3 \mathrm{~m}$ from the front of the stage.

In addition to the omnidirectional parameters, two spatial parameters were considered: $T S$, as shown in Eq. (2), and $T H$ as shown in Eq. (3), where $p_{\text {top }}, p_{\text {right }}, p_{\text {left }}$, and $p_{\text {back }}$ are pressures from each corresponding region:

$$
\begin{aligned}
& T S_{t_{l}-t_{u}}=10 \log \frac{\int_{t_{l}}^{t_{u}} p_{\text {top }}^{2}(t) \cdot \mathrm{d} t}{\int_{t_{l}}^{t_{u}}\left[p_{\text {left }}(t)+p_{\text {right }}(t)\right]^{2} \cdot \mathrm{d} t}, \\
& T H_{t_{l}-t_{u}}=10 \log \frac{\int_{t_{l}}^{t_{u}} p_{\text {top }}^{2}(t) \cdot \mathrm{d} t}{\int_{t_{l}}^{t_{u}}\left[p_{\text {left }}(t)+p_{\text {right }}(t)+p_{\text {back }}(t)\right]^{2} \cdot \mathrm{d} t} .
\end{aligned}
$$

The parameter TS compares sound energy received from top to that from sides over a time between a lower limit $\left(t_{l}\right)$ and an upper limit $\left(t_{u}\right)$, whereas the parameter $T H$ compares sound energy from top to that from horizontal (sides and back). The parameter $T H$, an extension of the earlier proposed $T S{ }^{7}$ is based on the premise that reflections from the back of a stage may also be relevant to musicians on stage, in addition to those from the sides. The inclusion of the back region underlines that on real stages, musicians are not orientated generally to the front of stage, and so the distinction between sides and back is somewhat arbitrary, unlike in previous laboratory work ${ }^{6}$ where the orientation of a musician could be more precisely defined. 
TABLE II. Summary of measured acoustic characteristics of the auditoria.

\begin{tabular}{|c|c|c|c|c|c|c|c|c|c|c|c|}
\hline Aud. & $\begin{array}{c}T_{30, \text { mid }}(\mathrm{s}) \\
\text { stalls }\end{array}$ & $\begin{array}{c}T_{30, \text { mid }}(\mathrm{s}) \\
\text { stage }\end{array}$ & $\begin{array}{l}\text { EDT, mid } \\
\text { (s) stage }\end{array}$ & $S T_{\text {Early }}(\mathrm{dB})$ & $S T_{\text {Late }}(\mathrm{dB})$ & $\begin{array}{c}G_{\text {Early }} \\
(\mathrm{dB})\end{array}$ & $\begin{array}{c}G_{\text {Late }} \\
(\mathrm{dB})\end{array}$ & $\begin{array}{c}T S \\
50 \mathrm{~ms} \\
(\mathrm{~dB})\end{array}$ & $\begin{array}{c}T S \\
100 \mathrm{~ms} \\
(\mathrm{~dB})\end{array}$ & $\begin{array}{c}\text { TH } \\
50 \mathrm{~ms} \\
(\mathrm{~dB})\end{array}$ & $\begin{array}{c}\text { TH } \\
100 \mathrm{~ms} \\
(\mathrm{~dB})\end{array}$ \\
\hline $\mathrm{AH}$ & 2.1 & 2.1 & 2.1 & -12.0 & -11.9 & 8.7 & 8.3 & 0.7 & 2.7 & -2.5 & 1.4 \\
\hline AP & 1.9 & 1.8 & 1.4 & -11.8 & -13.5 & 12.1 & 7.0 & 0.1 & 1.5 & -2.3 & 0.7 \\
\hline $\mathrm{HH}$ & 2.4 & 1.9 & 1.2 & -13.4 & -15.6 & 10.6 & 5.2 & 4.0 & 2.3 & 3.9 & 2.7 \\
\hline LH & 1.9 & 1.9 & 1.7 & -13.8 & -14.2 & 10.4 & 5.9 & 4.6 & 4.2 & 3.9 & 4.0 \\
\hline PH & 2.1 & 2.0 & 1.7 & -14.6 & -13.6 & 10.5 & 7.1 & -0.3 & -0.5 & -1.7 & -2.0 \\
\hline QC & 2.1 & 2.2 & 1.8 & -15.3 & -13.8 & 11.5 & 7.1 & -2.0 & -0.2 & -1.3 & -0.1 \\
\hline SO & 2.4 & 2.2 & 1.5 & -14.3 & -15.2 & 10.8 & 6.0 & 2.0 & 0.9 & 3.3 & 1.5 \\
\hline WH & 1.9 & 2.1 & 1.6 & -6.3 & -9.0 & 13.8 & 12.0 & 4.8 & 4.3 & 5.5 & 4.9 \\
\hline
\end{tabular}

The spatial parameters were power-averaged over $250-2000 \mathrm{~Hz}$ octave-bands for the 16 on-stage measurements with $1 \mathrm{~m}$ source-receiver distance. The region's top, sides (combination of "left" and "right") and horizontal (combination of left, right, and back) are found via spatial filtering using second order Ambisonics. These regions are defined as the solid angles subtended by the faces of a cube, such that if sound arrives through the top of the cube, it is assigned to the "top region," and similarly for the other faces. The cube is oriented so that the "front" faces toward the audience and the top faces toward the stage ceiling. The analysis procedure involves converting the 32 microphone signals from the Eigenmike into spherical harmonic channels, and then weighting and combining these channels to capture sound from a desired region, and reject sound from all other regions. ${ }^{7}$ For reference, the weights applied to each of the first nine Ambisonic channels (for first and second order analysis) are included in supplementary material. ${ }^{26}$ Last, the values of $T H$ are increased by $10 \log _{10}$ $\left(3^{2}\right)=9.54 \mathrm{~dB}$ to adjust for the one spatial region in the numerator compared with three spatial regions in the denominator, and the values of TS are similarly increased by $10 \log _{10}\left(2^{2}\right)$ $=6.02 \mathrm{~dB}$. While the Eigenmike's 32 microphones theoretically allow for up to fourth order Ambisonic analysis, choosing the appropriate microphone order involves balancing the ideal spatial selectivity with actual performance over the frequency range of interest. In Fig. 3, the directivity index (DI), which takes into account spatial aliasing and measurement noise, is shown, and was produced based on the method described in Ref. 29. The operational frequency range (over which DI is a constant) is approximately $900 \mathrm{~Hz}-7 \mathrm{kHz}$ for second order analysis and becomes progressively narrower for higher orders. Since the third and fourth order analyses are only valid over a narrow band (above the usual 250-2000 Hz octave-bands used for stage parameters), they were not considered further. The full $250-2000 \mathrm{~Hz}$ octave range is still used for $T S$ and $T H$ at second order analysis, despite being outside the optimum range for directivity (Fig. 3). Since first order analysis has constant DI over a wider frequency range (but with less directional selectivity than second order), a comparison of first and second order is also considered. In the inset in Fig. 3, results for TS and $\mathrm{TH}$ using first and second order analysis for upper time limits of 50 and $100 \mathrm{~ms}$ are compared, showing some agreement.

The lower time $\left(t_{l}\right)$ for $T S$ and $T H$ was selected to remove any influence of the direct sound and floor reflection, but still be before the arrival of stage enclosure reflections; the most appropriate values of $t_{l}$ were chosen individually for each hall and were in the range $12-15 \mathrm{~ms}$. The lower time limits were selected to be well after the occurrence of the direct sound (to ensure no effect from direct sound on the parameters), except in cases where early reflections occurred too close to $15 \mathrm{~ms}$, i.e., the lower time limit was selected as an optimum separation point between direct sound and reflection in each hall. Then in Table II, values for $T H$ and $T S$ are given with upper time limit $\left(t_{u}\right)$ set to both 50 and $100 \mathrm{~ms}$. The choice of upper time limit is further explored in Fig. 4 where the temporal evolution from 40 to $100 \mathrm{~ms}$ is shown for both $T S$ and $T H$, as well as for the sound energy level for regions Top, Sides, and Horizontal (relative to omnidirectional direct sound isolated using $0-10 \mathrm{~ms}$ ), adjusted to account for the number of spatial regions in the numerator and denominator in the same manner as for $T S$ and $T H$. In Fig. 4, the Top region plotted individually shows the arrival of reflections from above, occurring at various

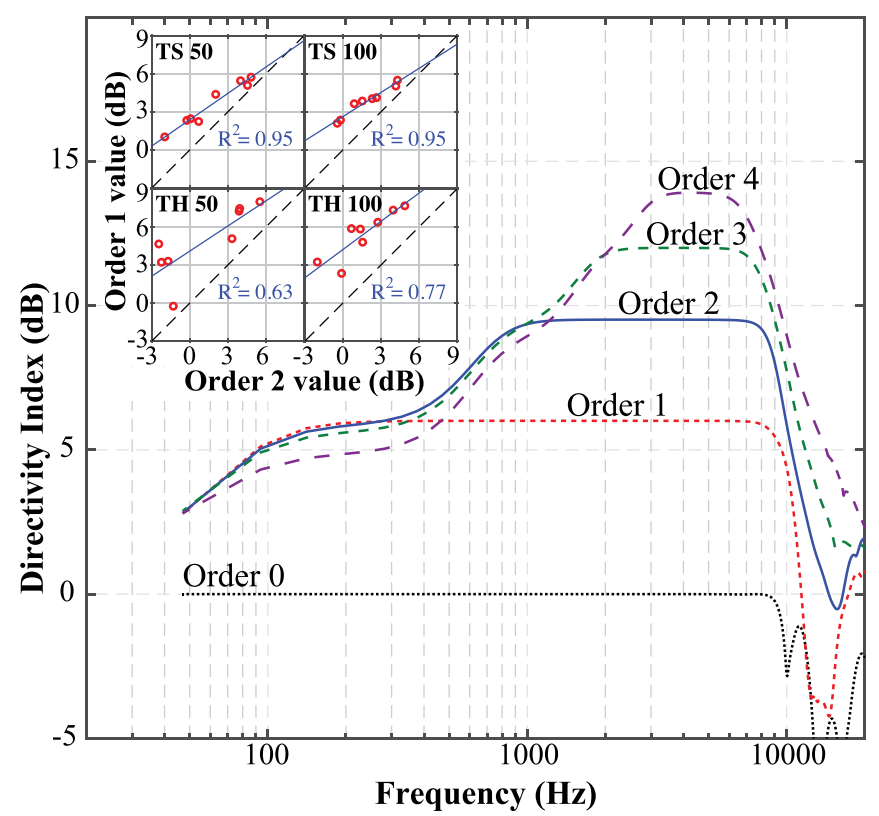

FIG. 3. (Color online) DI as a function of frequency for the Eigenmike with varying Ambisonics order. The inset charts compare first and second order Ambisonic analysis for stage average parameters TS and TH (power-averaged over $250-2000 \mathrm{~Hz}$ ), for $t_{u}$ set to both 50 and $100 \mathrm{~ms}$, separately. In each case the dashed line traces equality and the solid line is the linear regression line, with the coefficient of determination $\left(R^{2}\right)$ shown. 


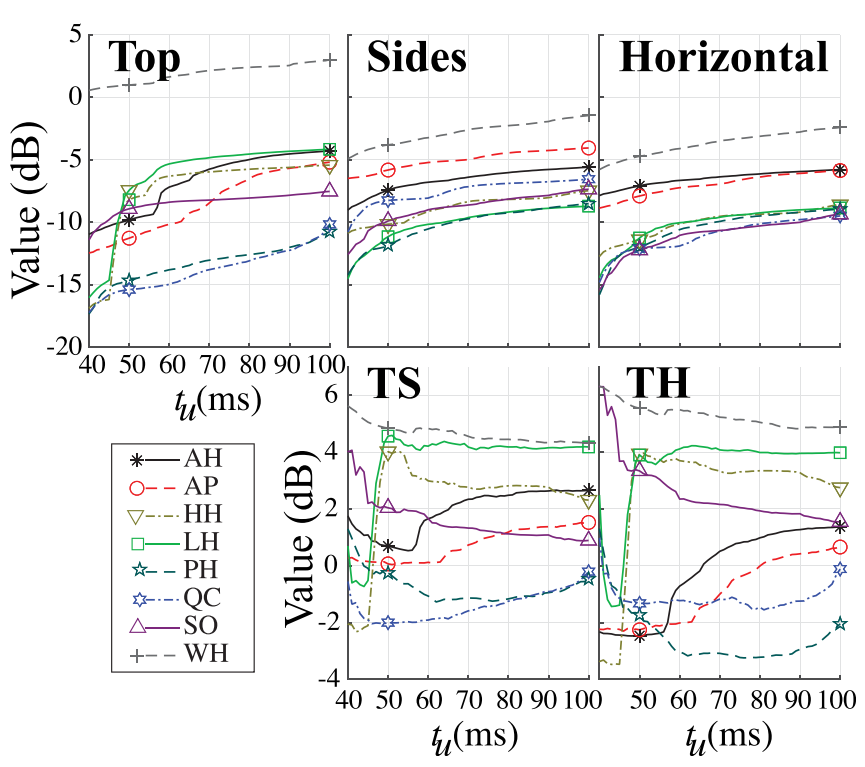

FIG. 4. (Color online) Effect of varying the upper time limit $\left(t_{u}\right)$ from $40 \mathrm{~ms}$ to $100 \mathrm{~ms}$ for sound energy of Top, Sides, and Horizontal (expressed with reference to direct sound from the omnidirectional channel over $0-10 \mathrm{~ms}$ ), and for the parameters $T S$ and $T H$. Markers are used for $t_{u}=50 \mathrm{~ms}$ and $t_{u}=100 \mathrm{~ms}$.

times for the halls, and in particular the absolute level for Top is high in WH compared to other halls.

In earlier work studying omnidirectional and spatiallydefined acoustic parameters, various upper time limits have been used to isolate "early" reflections, namely, $40 \mathrm{~ms}$, $50 \mathrm{~ms},{ }^{4} 80 \mathrm{~ms},{ }^{4}$ and $100 \mathrm{~ms}^{3}$ Guthrie $^{4}$ found an upper time limit of $40 \mathrm{~ms}$ correlated with musicians' impressions when considering a top/sides ratio, which was not the case when an upper limit of $100 \mathrm{~ms}$ was used (in line with the upper limit for $\left.S T_{\text {Early }}\right)$. Domínguez ${ }^{20}$ also found a preference for "close lateral" and "far ceiling" reflections in a study with soloists, whereas Dammerud ${ }^{4}$ found spatial distribution of sound on stage to be relevant to musicians by studying architectural parameters in a study with symphony orchestra musicians. An upper limit of $40 \mathrm{~ms}$ is possible in the current study, in line with Guthrie's work; however, as seen in Fig. 4 , a substantial amount of energy from Top arrives between 40 and $50 \mathrm{~ms}$ in several halls, which would be neglected if selecting an upper limit of $40 \mathrm{~ms}$. It is desirable that results are not sensitive to the exact choice of cutoff, hence a cutoff in the range $40-50 \mathrm{~ms}$ was avoided. Furthermore, from Fig. 4, the evolution of both $T H$ and $T S$ for $\mathrm{HH}, \mathrm{LH}, \mathrm{SO}$, and $\mathrm{WH}$ is such that the ratios are relatively high over the whole range of 50-100 ms, whereas for $\mathrm{AH}, \mathrm{AP}, \mathrm{PH}$, and $\mathrm{QC}$ the ratios are considerably lower at $50 \mathrm{~ms}$, and slowly increase toward $100 \mathrm{~ms}$. Overall, the energy from Top arrives early in $\mathrm{HH}, \mathrm{LH}, \mathrm{SO}$, and WH compared to the other halls in the dataset. To further examine any relationship between OAI, and $T S, T H$, upper limits of both $t_{u}=50 \mathrm{~ms}$, and $t_{u}=100 \mathrm{~ms}$ (as used by $S T_{\text {Early }}$ ) will be used in further analyses.

To complement the spatial acoustic parameters, some simple architectural measures were considered, as defined in Fig. 2, including: $D, H$, and $W$; and three ratios: $H / W, H / D$, and $H / \sqrt{(D W)}$. These ratios are crude proxies for the spatially-defined stage parameters since they account for the distance to reflecting objects at the top, sides, and back of the stage, but not the complexity of the stage enclosure itself (such as any scattering or absorbing properties). Note that on stages without a stage enclosure, it may be difficult to accurately characterize width to reflecting surfaces at side of stage $(W)$. Likewise, in cases with overhead reflectors, the height to reflecting surface above stage $(H)$ may be difficult to accurately represent with a single number. These architectural parameters and other hall properties are summarized in Table III, and Fig. 5 shows scale stage diagrams. Photographs of the halls are included in the supplementary material. ${ }^{26}$ As the current study focused on chamber ensembles, which play using primarily the front portion of the stage, the architectural measures were defined accordingly. Dammerud $^{4}$ used similar architectural parameters $W, H\left(W_{r s}\right.$, and $H_{r b}$, respectively, in Dammerud ${ }^{4}$ ) and $D$, defined to account for the distance to reflecting surfaces at both the front and back of the stage, as the focus of his study was larger symphony orchestras. Dammerud also considered ratios of height and width $(H / W)$, and a ratio of depth and width $(D / W)$, but did not consider $H / D$.

\section{Statistical analysis}

The statistical analysis was performed using the software R. ${ }^{30}$ Data management and graphics were generated using the package tidyverse. $^{31}$

TABLE III. Auditorium information, including physical sizes and proportions of the measured auditoria. Except where indicated, stage extensions were not used. Note that at least $3500 \mathrm{~m}^{3}$ of the volume of LH was semi-occluded by the stage shell and ceiling reflectors. Parenthesized dates indicate the date of the most recent renovation prior to the musician survey and acoustic measurements.

\begin{tabular}{|c|c|c|c|c|c|c|c|c|c|c|}
\hline Hall ID & $\begin{array}{l}\text { Date constructed } \\
\text { (and refurbished) }\end{array}$ & $\begin{array}{l}\text { Room volume } \\
\qquad\left(\mathrm{m}^{3}\right)\end{array}$ & Stage features & $W(\mathrm{~m})$ & $D(\mathrm{~m})$ & $\begin{array}{l}\text { Stage area } \\
\qquad\left(\mathrm{m}^{2}\right)\end{array}$ & $H(\mathrm{~m})$ & $H / W$ & $H / D$ & $H / \sqrt{(D W)}$ \\
\hline $\mathrm{AH}$ & 1866 & 9800 & Stage extension used & 20.2 & 7.3 & 120 & 11.4 & 0.56 & 1.56 & 0.94 \\
\hline AP & 1999 & 10600 & Stage extension used & 13.0 & 9.2 & 100 & 12.0 & 0.92 & 1.30 & 1.10 \\
\hline $\mathrm{HH}$ & $1982(2010)$ & 27000 & $\begin{array}{c}\text { Adjustable acoustic ceiling } \\
\text { and back wall }\end{array}$ & 19.1 & 7.3 & 120 & 9.5 & 0.50 & 1.30 & 0.80 \\
\hline LH & 1976 & 28500 & Adjustable stage shell & 19.5 & 8.0 & 140 & 9.8 & 0.50 & 1.23 & 0.78 \\
\hline PH & 1973 & 18800 & & 18.2 & 11.1 & 180 & 16.5 & 0.91 & 1.49 & 1.16 \\
\hline QC & 1985 & 22400 & & 16.4 & 14.7 & 235 & 17.3 & 1.05 & 1.18 & 1.11 \\
\hline SO & 1973 (2010) & 26400 & Suspended reflectors & 20.5 & 11.5 & 200 & 9.0 & 0.44 & 0.78 & 0.59 \\
\hline WH & $1887(2011)$ & 13000 & Stage extension used & 12.0 & 7.1 & 90 & 5.8 & 0.48 & 0.82 & 0.63 \\
\hline
\end{tabular}




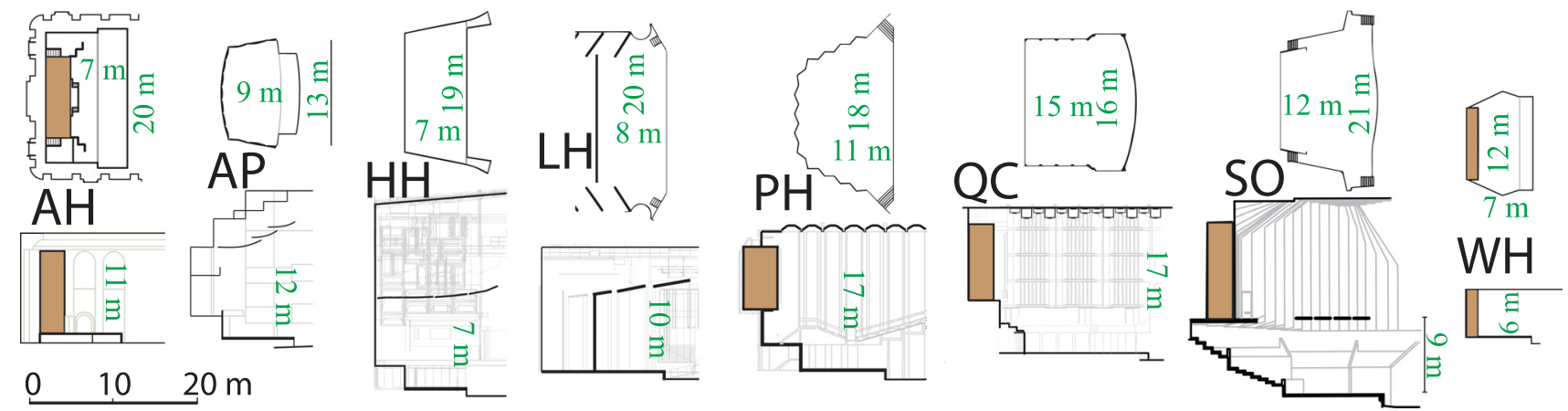

FIG. 5. (Color online) Auditorium stage plans, as configured for the chamber orchestra performances and acoustic measurements. Plans are oriented with downstage toward the right of the figure. Pipe organs are indicated by brown shading.

\section{Analysis of the subjective data}

The questionnaire used in the current study contained 11 items, with intercorrelation between the musicians' ratings for these items. Hence, Principal Component Analysis was used to explore the possibility of data reduction into a smaller set of orthogonal "principle components" (PCs). ${ }^{32}$ The parallel analysis (PA) method, ${ }^{33}$ which is a Monte-Carlo test for determining significant eigenvalues, was used to determine the number of PCs to retain, since it has been shown to be one of the most accurate methods, compared to the alternatives. ${ }^{33}$ PA was conducted using the function rawpar from the package paramap, ${ }^{34}$ with 10000 permutations of the original data, and using the 95th percentile of the distribution of the PA random eigenvalues to determine the number of PCs. The PA showed that only one PC should be retained, indicating that the musicians were assessing the halls primarily on one dimension-something similar to the OAI (note that PA without the OAI scale in the questionnaire produced the same result). This finding is similar to earlier studies that have used a comparable questionnaire, and where several items loaded onto only one or two "dimensions.",3,4 Moreover, the current questionnaire included OAI as a separate scale (0-10; "Very Poor"-"Very Good"), which is strongly correlated to the mean of all other ratings (Spearman's $r=0.8$ ); the latter being the finding in previous studies too. ${ }^{4,14}$ Hence, the subsequent analysis mainly focuses on the OAI ratings in the original questionnaire (instead of a single PC, as per the PA), which also allows easier comparisons with previous studies that used a similar questionnaire ${ }^{4,10}$ to the current. Note that Kalkandjiev and Weinzierl ${ }^{17}$ reported five factors that are relevant to musicians, based on a 22-item questionnaire that was designed after extensive consultation with musicians. Their methodology and their findings, while important and exemplary for future work in this field, are nevertheless of limited use in the current study as the current questionnaire was based on previous studies ${ }^{3,4,10}$ with a smaller set of questions. The choice to limit the current questionnaire to 11 items was mainly to avoid musician fatigue, when completing questionnaires during a touring schedule.

\section{Modeling of OAI}

Robust mixed-effects models were used to study the relationship between musicians' OAI ratings, and the various objective parameters. The "robustness" of the models refers to minimizing the influence of outlying values in the data. ${ }^{35}$ The use of mixed-effects models allowed incorporating the repeated-measures design (i.e., non-independent, autocorrelated data per musician) of the study. Herein, the randomeffects due to the musicians are explicitly modelled, by allowing the intercepts to vary per musician, alongside the fixed-effects of the objective parameters. The objective parameters (i.e., the predictors in models) included the architectural, omnidirectional, and spatial parameters of the halls, and the interaction of the latter two. Models with both linear and parabolic terms for the fixed-effects were tested, wherever necessary. The mixed-effects modeling was performed using the rlmer function from the robustlmm package, ${ }^{35}$ and the $99 \%$ CIs for the predictors not crossing the null value of 0 was considered statistically significant. Wald CIs were used as they assume a multivariate normal sampling distribution for the objective parameters, which is a much weaker, and a more appropriate assumption here than the parametric assumption (not to be confused with modeling 'parameters') for the residuals. To compare the goodness-of-fit between the various models of OAI, conditional $R^{2}$ values for the robust mixed-effects models were used, as described in Ref. 36 , and calculated as

$$
R_{\mathrm{RMM}}^{2}=\frac{\sigma_{f}^{2}+\sigma_{\alpha}^{2}}{\sigma_{f}^{2}+\sigma_{\alpha}^{2}+\sigma_{\varepsilon}^{2}} .
$$

In Eq. (4), $\sigma_{f}^{2}$ is the variance explained by the fixed-effects, $\sigma_{\alpha}^{2}$ is the random-effects variance (normally distributed with mean zero), and $\sigma_{\varepsilon}^{2}$ is the residual-error variance (also a random-effect). The $R_{\text {RMM }}^{2}$ values are provided with their bootstrapped $95 \%$ CIs (599 bootstrap samples, with replacement), calculated using the functions boot, and boot.ci from the package boot. Bias-corrected and accelerated CIs are provided, which correct for any skewness in the bootstrapped distribution. ${ }^{37}$

\section{RESULTS AND DISCUSSION}

\section{A. Regression models}

For brevity, results for only those robust mixed-effects (Table IV) that had statistically significant fixed-effects coefficients are presented and discussed. The bootstrapped 95\% CIs of $R_{\mathrm{RMM}}^{2}$ values of some of these models contained the 
TABLE IV. Robust mixed-effects regression models for predicting the OAI. Characters $a-d$ represent the fixed-effects coefficients, with their standard errors in brackets. $\alpha$ represents the standard deviations for the random-effects. $\varepsilon$ is the standard deviation for the residual error. $R_{\mathrm{RMM}}^{2}$ is the goodness-of-fit of mixedeffect models, calculating using Eq. (4). $R_{\mathrm{RMM}}^{2} 95 \%$ bootstrapped CIs not crossing the null value of 0 are highlighted in bold.

\begin{tabular}{|c|c|c|c|c|c|c|c|c|}
\hline \multirow[b]{2}{*}{ Model } & \multirow[t]{2}{*}{ Predictor(s) } & \multicolumn{4}{|c|}{ Fixed-effects } & \multicolumn{2}{|c|}{ Random-effects } & \multirow[b]{2}{*}{$R_{\mathrm{RMM}}^{2}$} \\
\hline & & $a$ & $b$ & $c$ & $d$ & $\alpha$ & $\varepsilon$ & \\
\hline \multicolumn{9}{|c|}{ Architectural parameters } \\
\hline$(\mathrm{i})^{\mathrm{a}}$ & $H / W$ & $5.48(0.60)$ & $2.34(0.75)$ & & & 0.51 & 1.89 & $0.11(0.00,0.19)$ \\
\hline$(\mathrm{ii})^{\mathrm{b}}$ & $(H / W)+(H / W)^{2}$ & $-16.45(2.82)$ & $69.36(8.46)$ & $-46.18(5.77)$ & & 0.66 & 1.49 & $0.46(0.34,0.50)$ \\
\hline (iii) $^{\mathrm{a}}$ & $H / D$ & 2.14(0.72) & $3.94(0.56)$ & & & 0.61 & 1.59 & $0.36(0.18,0.43)$ \\
\hline (iv) $)^{a}$ & $H / \sqrt{D W}$ & $3.20(0.70)$ & $4.28(0.74)$ & & & 0.56 & 1.67 & $0.25(0.10,0.32)$ \\
\hline$(v)^{\mathrm{a}}$ & $H$ & $4.88(0.58)$ & $0.19(0.05)$ & & & 0.49 & 1.84 & $0.13(0.00,0.22)$ \\
\hline \multicolumn{9}{|c|}{ Omnidirectional acoustic parameters } \\
\hline$(v i)^{b}$ & $S T_{\text {Early }}+\left(S T_{\text {Early }}\right)^{2}$ & $-5.44(2.70)$ & $-2.42(0.53)$ & $-0.11(0.02)$ & & 0.00 & 1.89 & $0.16(0.03,0.19)$ \\
\hline$(\text { vii })^{b}$ & $S T_{\text {Late }}+\left(S T_{\text {Late }}\right)^{2}$ & $-28.32(5.21)$ & $-5.95(0.85)$ & $-0.24(0.03)$ & & 0.49 & 1.68 & $0.35(0.25,0.38)$ \\
\hline \multicolumn{9}{|c|}{ Spatial acoustic parameters } \\
\hline$(\text { viii })^{\mathrm{a}}$ & $T S_{50}$ & $7.58(0.23)$ & $-0.30(0.07)$ & & & 0.48 & 1.83 & $0.14(0.01,0.22)$ \\
\hline$(\mathrm{ix})^{\mathrm{a}}$ & $T S_{100}$ & $7.57(0.29)$ & $-0.28(0.10)$ & & & 0.48 & 1.94 & $0.09(0.00,0.18)$ \\
\hline$(\mathrm{x})^{\mathrm{a}}$ & $\mathrm{TH}_{50}$ & $7.33(0.20)$ & $-0.32(0.05)$ & & & 0.53 & 1.62 & $0.31(0.12,0.38)$ \\
\hline$(\mathrm{xi})^{\mathrm{a}}$ & $T H_{100}$ & $7.64(0.23)$ & $-0.39(0.07)$ & & & 0.54 & 1.75 & $0.23(0.09,0.30)$ \\
\hline \multicolumn{9}{|c|}{ Interaction of spatial and omnidirectional acoustic parameters } \\
\hline$(\text { xii) })^{\mathrm{c}}$ & $S T_{\text {Early }} \times T S_{100}$ & $22.65(3.34)$ & $1.06(0.23)$ & $-4.01(0.80)$ & $-0.25(0.05)$ & 0.44 & 1.80 & $0.24(0.12,0.31)$ \\
\hline$(\mathrm{xiii})^{\mathrm{c}}$ & $S T_{\text {Late }} \times T S_{100}$ & $30.04(2.67)$ & $1.58(0.19)$ & $-6.05(0.72)$ & $-0.41(0.05)$ & 0.63 & 1.51 & $0.47(0.32,0.51)$ \\
\hline$(\mathrm{xiv})^{\mathrm{c}}$ & $S T_{\text {Early }} \times T H_{100}$ & $17.69(2.07)$ & $0.72(0.15)$ & $-2.40(0.45)$ & $-0.14(0.03)$ & 0.54 & 1.61 & $0.37(0.25,0.43)$ \\
\hline$(x v)^{c}$ & $S T_{\text {Late }} \times T H_{100}$ & $22.15(2.15)$ & $1.05(0.15)$ & $-3.69(0.55)$ & $-0.25(0.04)$ & 0.65 & 1.50 & $0.48(0.36,0.51)$ \\
\hline
\end{tabular}

${ }^{\mathrm{a}}$ Linear model for a single predictor $(x)$ : OAI $=(a+\alpha)+(b \times x)+\varepsilon$.

${ }^{\mathrm{b}}$ Parabolic model for a single predictor $(x)$ : OAI $=(a+\alpha)+(b \times x)+\left(c \times x^{2}\right)+\varepsilon$.

${ }^{\mathrm{c}}$ Model for two predictors $(x, y)$, and their interaction: OAI $=(a+\alpha)+(b \times x)+(c \times y)+(d \times x: y)+\varepsilon$.

null-value of 0 -representing a weak model overall. These models are nevertheless presented since some of them have relevance for comparison with previous research (e.g., Ref. 4 noted relevance for a linear model with $H / W$ ). A secondary reason is that it is likely that with a larger sample of halls and musicians, some of these $R_{\mathrm{RMM}}^{2}$ CIs may change, as the bootstrap method, despite its advantages that include robustness and not making distributional assumptions, still needs a fairly representative sample to begin with. None of the other fixed-effects, nor their interactions, reached significance.

The residual plots for all the models reported in Table IV were visually inspected for homoscedasticity, linearity, etc., and no noticeable bias was found, i.e., the model coefficients and predictions are unbiased. The low $R_{\mathrm{RMM}}^{2}$ values presented in Table IV, especially for models with just one predictor, are typical of studies of human behaviour in complex settings, where a majority of variance remains unexplained. All the previous research where the relationship between objective acoustic parameters and subjective parameters, including OAI, has been studied have used orchestra-averaged values (i.e., ignoring the repeated-measures design, and potentially biased mean values), and have mostly provided correlation coefficients (Pearson's $r$, without any justification for using a parametric test). ${ }^{3,4,10}$ Although squaring the $r$ values in these studies can be used to derive $R^{2}$ values for single-predictor models, these $R^{2}$ values are not directly comparable to the corresponding $R_{\mathrm{RMM}}^{2}$ values reported here. The $R_{\mathrm{RMM}}^{2}$ values explicitly model the variance due to the repeated measurements on the musicians, which is a more suitable method in general, compared to using orchestra-averaged OAI, or other subjective parameters (see Sec. II A). Nevertheless, $R^{2}$ values from previous studies for linear models are presented for completeness, where applicable in the following. Note that the current results are specific to chamber ensembles. The aim of comparisons, and in general, referring to previous studies that included different musician groups, e.g., symphony orchestras, in the following only goes as far as addressing the common theme of stage acoustics for musicians. The applicability of specific results from the current study for musician groups other than chamber ensembles will need future validation.

\section{B. Subjective relevance of omnidirectional parameters}

When used as predictors in linear models, none of the omnidirectional parameters considered here, i.e., $T_{30}$, $S T_{\text {Early }}, S T_{\text {Late }}$, EDT, $G_{\text {Early }}$, and $G_{\text {Late }}$, significantly predicted OAI ratings. The importance of reverberation time for audience and musicians alike has been established in the past. ${ }^{3,4,38}$ However, there was little variation in reverberation times in the halls that were sampled: $T_{30}$ (mid) on stage was between 1.8 and $2.2 \mathrm{~s}$ (shorter reverberation times in smaller auditoria). The fact that these halls were purpose-built with appropriate reverberation times may have suppressed any relationship that can be expected between $T_{30}$ and OAI.

Despite being recognized for its role as a stage acoustic parameter, ${ }^{3,9}$ the subjective relevance of $S T_{\text {Early }}$ has been questioned recently. ${ }^{4,39}$ In the current study, and within a linear model, $S T_{\text {Early }}$ did not significantly predict OAI; 
however, it was noted $S T_{\text {Early }}$ in WH was much higher compared to the other halls. The musicians generally commented that the WH stage was "too live," and this perhaps reflected in the lower rating of OAI for this hall; there was also a large variance in the OAI ratings in $\mathrm{WH}$ and QC (which did, however, fit a linear trend). Excluding $\mathrm{WH}$, the $3.5 \mathrm{~dB}$ range for $S T_{\text {Early }}$ for the remaining halls in the current study is comparable to the approximately $4 \mathrm{~dB}$ range for the halls in the three studies by Gade, ${ }^{3}$ which included symphony orchestras ( $S T_{\text {Early }}$ was then known as ST1). For WH excluded, there are significant linear relationships between $S T_{\text {Early }}$ and subjective scales of OAI, ensemble, and support scales considered individually, with almost identical, and very small, effect-sizes $\left(R_{\mathrm{RMM}}^{2}=0.11,0.13,0.10\right.$, respectively); linear model of $S T_{\text {Early }}$ as a predictor, with "hearing self" scale as the response variable was not significant. In comparison, $\mathrm{Gade}^{3}$ reported high correlation coefficients between subjective scales "ensemble_-hearing others" and "ensemblehearing self" and $S T_{\text {Early }}$ in two of his three studies with symphony orchestras in concert halls: $r>0.69$, which gives $R^{2}>0.48$, although the $R^{2}$ adjusted for the sample size would be lower; also, note the caveat about using $r$ from Sec. III A. Furthermore, a parabolic model for OAI and $S T_{\text {Early }}$ (WH included) significantly predicts OAI, albeit within a weak model (Fig. 6; Table IV, 95\% CIs of the $R_{\mathrm{RMM}}^{2}$ value almost touching 0 ). However, by visual inspection of the plot between $S T_{\text {Early }}$ and OAI (Fig. 6), it is hard justifying the use of a parabolic relationship simply to accommodate $\mathrm{WH}$ in what otherwise looks like a relatively linear relationship.

Arguably, $S T_{\text {Early }}$ may never have been intended as a predictor of musicians' assessments of the OAI of stages. ${ }^{39}$ Nevertheless, the current and previous findings $\mathrm{s}^{3,4}$ indicate that musicians' assessments of several aspects of hearing and playing (ensemble, support, etc.) are highly correlated, with a single "dimension" - the OAI, accounting for the majority of variance (the main exception being Ref. 17, wherein a more exhaustive assessment of musicians' subjective assessments implies that there may be dimensions other than OAI that need to be considered). In that regard, insofar as the OAI of stage assessments is concerned, $S T_{\text {Early }}$ may only be considered as a weaker predictor compared to spatial, and some architectural parameters (Table IV; also see Sec. III C) in a parabolic (not linear) model, and may similarly account for particular aspects of ensemble and support. The current findings for chamber ensembles are partly consistent with those reported for symphony orchestras by Dammerud, for Dammerud's and Cederlöf's ${ }^{10}$ combined data (Table 8.9 in Dammerud $^{4}$ ), where for a $6.5 \mathrm{~dB}$ range in the $S T_{\text {Early values, }}$ the correlation coefficient with OAI ratings was quite small ( $r=0.16$ in Ref. 4 , i.e., $R^{2}=0.03$ ). Overall, perhaps a more reasonable assessment of the role of $S T_{\text {Early }}$ as a predictor of OAI, and other relevant subjective scales, is best suited to a future study with a suitably large range of $S T_{\text {Early. }}$.

$S T_{\text {Late }}$ also did not significantly predict OAI using a linear mixed-effects model. However, similar to $S T_{\text {Early, }}$ after removing $\mathrm{WH}$, a significant linear relationship was found between $S T_{\text {Late }}$ and OAI (Table IV), with an identical, and quite small, effect size as $S T_{\text {Early }}\left(R_{\mathrm{RMM}}^{2}=0.11\right)$. Gade's ${ }^{3}$
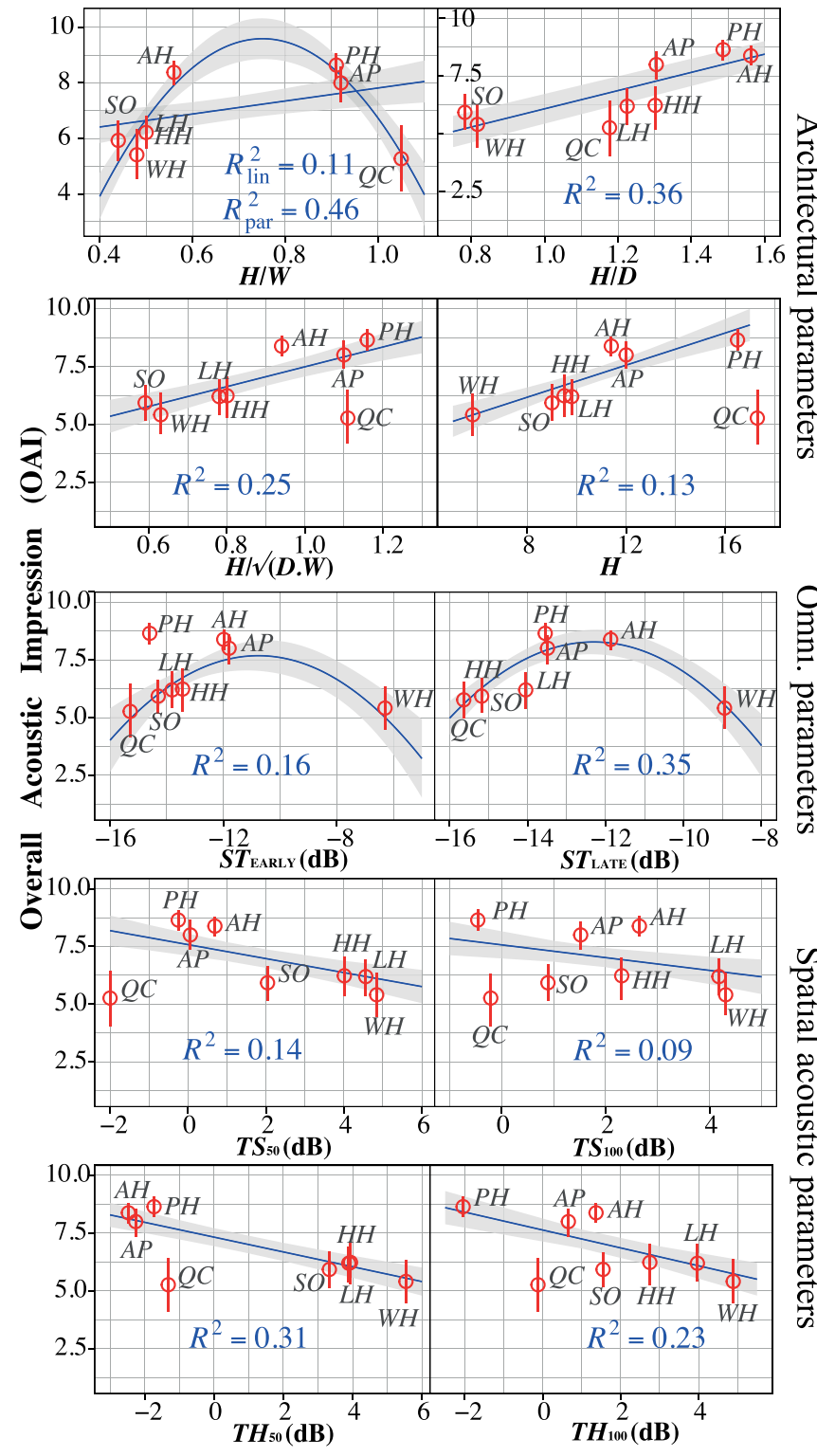

FIG. 6. (Color online) The relationship between various objective parameters and OAI, based on the models in Table IV. The three types of objective parameters - architectural, omnidirectional, and spatial-are grouped. For each hall, the mean OAI scores are presented with their non-parametric bootstrapped 95\% CIs. The linear and/or parabolic models are presented with their standard errors. The models of OAI predicted using the interaction of omnidirectional and spatial parameters from Table IV are not included here.

original work did not consider $S T_{\text {Late }}$, whereas Dammerud reported high $r$ between $S T_{\text {Late }}$ and an orchestra-averaged subjective reverberance scale $\left(r=0.75\right.$, or $R^{2}=0.56$; note the caveat about using $r$ from Sec. III A), and OAI ( $r=0.65$, or $R^{2}=0.42$ ) in the second survey (Table VIII.6 in Ref. 4 ). In the current study, $R_{\mathrm{RMM}}^{2}$ values for the relationship between $S T_{\text {Late }}$ and the Reverberance scale were 0.20 and 0.29 for data with $\mathrm{WH}$ included and excluded, respectively. Similar to $S T_{\text {Early }}, S T_{\text {Late }}$ was found to significantly predict OAI using a parabolic mixed-effects model (Table IV); however, from Fig. 6 it is clear that without WH, a linear relationship would be selected over a parabolic relationship. Again, as was done for $S T_{\text {Early, it can be argued here that }}$ $S T_{\text {Late }}$ was never meant to predict OAI, and the current findings give support to the use of $S T_{\text {Late }}$ as a predictor of 
subjective Reverberance for chamber ensembles, similar to Dammerud's findings for symphony orchestras. ${ }^{4}$

Last, $G_{\text {Early }}$ and $G_{\text {Late }}$, measured across-stage, were tested as alternatives to the support measures (as used by Dammerud $^{4}$ ), but provided similar information about WH as the $S T$ parameters and did not predict OAI in other halls.

\section{Subjective relevance of spatial parameters}

The linear relationships between OAI and both TS and $T H$ with upper time limits of 50 and $100 \mathrm{~ms}$ were considered, and were significant (Table IV). Among these, the largest effect-size was observed for $T H$ with a $50 \mathrm{~ms}$ cutoff (Table IV, $R_{\mathrm{RMM}}^{2}=0.31$ ), which is also the strongest among linear models with a single acoustic parameter. Note that the use of $H / D$ as a predictor of OAI, which, along with $H / \sqrt{(D W)}$, more-or-less encapsulate the same idea as $T H$ although within a gross architectural sense, provided the strongest linear model with a single parameter overall. In general, the $T H$ models had larger effect-sizes (more than twice) than the corresponding TS models for the two upper time limits of 50 and $100 \mathrm{~ms}$, with the $100 \mathrm{~ms}$ models being weaker models.

When examining the relationship between OAI, and TS and $T H$, respectively (both 50 and $100 \mathrm{~ms}$ cutoffs) using Fig. 6 , the hall QC appears as an outlier from a linear trend, as was the case for $\mathrm{WH}$ when considering the $S T$ parameters. It should be noted there was considerably more variance in the musicians' OAI ratings for QC (well-liked by most, but strongly disliked by some). However, the mixed-effects model can account for this variance, rather than taking an orchestra average or median, as used in initial analysis of the current data in Ref. 7, and in some previous studies. ${ }^{3,4}$ The relationship between $T H$ and OAI is shown in Fig. 6 with higher OAI ratings (mean values between approximately 8-9, except for QC) corresponding to lower $T H$ values (approximately $-2 \mathrm{~dB}$ ), and vice versa. The presence of two groups, with high and low OAI ratings with respect to $T H$ values, is noteworthy and shows some promise in terms of suggesting recommended values for stages. However, since the current dataset did not feature any $T H$ values between approximately -1 and $3 \mathrm{~dB}$, the grouping of halls into good and bad (and anything in between) based on their $T H$ values is considered a bit ambitious at this stage. Crucially, based on the current results and the fact that the TH parameter is more inclusive than TS in representing early sound from all horizontal directions (except, of course, the front), future studies are recommended, where a wider and less sparse range of the $T H$ parameter is studied.

The subjective relevance of spatial distribution of sound on stage characterized by spatial parameters found here agrees with earlier studies using auralization in a laboratory setting. ${ }^{6,20}$ Domínguez $^{20}$ observed that soloists preferred close lateral reflection and far ceiling reflections. Guthrie ${ }^{6}$ found a relationship between $L Q_{7-40} \mathrm{Top} / \mathrm{Sides}$ and OAI ratings of 17 musicians under conditions replicating ensemble playing conditions. Guthrie's findings support the idea that even for smaller ensembles, the ratio of sound energy from above to that from the sides is important, which is consistent with current findings for both small and large chamber music ensembles. The parameter $L Q_{7-40} \mathrm{Top} / \mathrm{Sides}$ excludes reflections from the back, which can be more easily justified in a laboratory study where the orientation of musicians is known. Also note that $L Q_{7-40}$ Top/Sides used a different method of spatial filtering, and the definitions of spatial regions were not based on solid angles subtended by the faces of a cube as in current work, but rather more complex spatial regions, resulting in additional regions on the sphere where reflections were actually neglected. Guthrie's study also examined a Top/Sides ratio with a $100 \mathrm{~ms}$ upper time

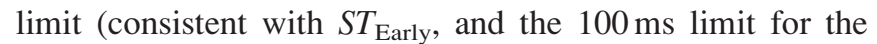
spatial parameters here), but this was not found to predict musicians' impressions. This is consistent with the results here, which finds a stronger relationship between OAI and both $T H$ and $T S$ for a lower time-limit of $50 \mathrm{~ms}$, than for $100 \mathrm{~ms}$. As discussed in Sec. II C, $40 \mathrm{~ms}$ was not used as the upper time limit in the current study due to substantial stage reflections arriving within the $40-50 \mathrm{~ms}$ period. Overall, based on the findings in this study, as well as earlier work, it appears using a lower cutoff time than $100 \mathrm{~ms}$ for studying spatial parameters may be particularly useful in determining musicians' preferred conditions. The current findings support the use of an upper limit of $50 \mathrm{~ms}$ (Sec. II C, Table IV, Fig. 6).

\section{Subjective relevance of architectural parameters}

Several architectural measures were considered here, which represent highly simplified, complementary versions of the spatial acoustic parameters, and broadly encapsulating the idea of studying the relative importance of vertical and horizontal stage reflections. The dimension $H$ (stage height) alone showed a relatively weak linear relationship with OAI (Table IV, with $95 \%$ CI of $R_{\mathrm{RMM}}^{2}$ crossing 0 ). The ratio $H / W$, which was previously considered for studies with symphony orchestras by Dammerud ${ }^{3}$ (high $r$ therein), and Gade ${ }^{39}$ (low $r$ therein), had a weaker linear relationship with OAI in the current study (Table IV, with $95 \%$ CI of $R_{\mathrm{RMM}}^{2}$ crossing 0 ), but a stronger parabolic relationship (Table IV). Last, for linear models, the ratios $H / \sqrt{(D W)}$ and $H / D$ showed stronger relationships with OAI (Table IV) compared to a linear relationship with $H / W$, with $H / D$ providing the strongest linear model overall. This agrees with the finding of stronger relationship between OAI and $T H$, compared to that between OAI and $T S$, with $H / D$ and $H / \sqrt{(D W)}$ being crude approximations of $T H$, and $H / W$ being a crude approximation of TS.

Furthermore, inspecting Fig. 6, QC appears to be creating the parabolic relationship for $H / W$. Excluding QC, a linear relationship appears more reasonable for $H / W$; however, excluding QC will also improve the fits for other architectural measures $[H, H / D$, and $H / \sqrt{(D W)}]$. While ultimately a parabolic (or, in general, a nonlinear) relationship can be expected between OAI and all the architectural parameters listed here, linear models seem sufficient for the current dataset-in that regard, the ratios $H / D$ (particularly) and $H / \sqrt{(D W)}$ are better predictors than $H / W$. 


\section{E. Subjective relevance of interactions between omnidirectional and spatial parameters}

While considering the combinations of acoustic parameters (Table IV), it was not assumed that such combinations were concomitant in terms of musicians' assessments. Instead, the aim was to explore whether certain plausible combinations accounted for more of the variance in the data. Furthermore, $T S$ and $T H$ with only an upper cutoff set to $100 \mathrm{~ms}$ were studied in interaction with $S T_{\text {Early }}$ and $S T_{\text {Late }}$ for consistency and simplicity, since a $100 \mathrm{~ms}$ cutoff underlies the upper limit for the former, and the lower limit for the latter; models with $50 \mathrm{~ms}$ cutoff provided similar results (not presented here). These models all predicted OAI reasonably well, particularly in the case of interaction between $S T_{\text {Late }}$ and TS/TH (Table IV). These models, in very simple terms, suggest that a combination of the earlier spatially directive part (up to $100 \mathrm{~ms}$ as shown in Table IV, or similarly for $50 \mathrm{~ms}$ ) and the latter omnidirectional part (beyond $100 \mathrm{~ms}$ ) of the hall's response may hold promise as providing a more comprehensive account of the OAI of musicians. Inspecting the signs of the regression coefficients, OAI is expected to increase with increasing values of omnidirectional, and decreasing values of spatial parameters, and vice versa. However, as noted for the constituent parameters of these models (e.g., $S T_{\text {Early }}, T H$, etc.), future studies with a more uniform spread of these parameters are needed to investigate their interactions further.

\section{F. General discussion and recommendations}

Although the significant relationship between OAI and spatially-defined acoustic parameters appears to show that the latter are useful in assessing musicians' preferences, some limitations should be noted. The ratios consider only the relative levels of reflections from above, the sides and horizontally, not the absolute level for each case. In extreme cases with very few, or no early reflections from either direction, the ratio may not identify this. As noted by others, ${ }^{4}$ there may be cases where a ceiling reflection is preferable to no early reflections at all. Hence, a prerequisite for these parameters to be useful is that the energy of early reflections (omnidirectional) is within an appropriate range, which is indicated by $S T_{\text {Early }}$ (or an equivalent $G_{\text {Early }}$ ). Furthermore, it should be noted that increasing the $T S$ and $T H$ parameter (and similar architectural ratios) can improve OAI up to a point, but there will be a limit to the relationship, beyond which increased stage ceiling height while keeping the other dimensions unchanged does not improve OAI. This was investigated with the use of linear and parabolic relationships in the mixed-effects models, but more definitive guidelines regarding the use of these parameters for practical purposes may only be possible after future studies with larger sample sizes for halls, musicians, and more uniform spread of parameters values in halls. With that in mind, in the current study, the group of well-liked halls (AP, AH, and $\mathrm{PH})$ are noted as having $H / D$ of at least 1.3 , and $T H(50 \mathrm{~ms})$ of between -2.5 and $-1.7 \mathrm{~dB}$, as well as $T_{30}$ between 1.9 and $2.1 \mathrm{~s}$ on stage, and these values could be used as tentative guidelines for preferred stage conditions for chamber ensembles, in conjunction with the suggested range for the earlier proposed $S T_{\text {Early }}$ parameter. ${ }^{3,39}$

In the current study, the acoustic stage measurements were made without stage furniture and musicians. Thus, any influence of the chamber orchestra itself on stage was not accounted for. Earlier work for both symphony ${ }^{40}$ and chamber ${ }^{41}$ orchestras has shown that the presence of the orchestra on stage attenuates early reflections from the stage enclosure, and attenuation of first-order reflections of $2-5 \mathrm{~dB}$ at $1000 \mathrm{~Hz}$ has been found with a chamber orchestra present on stage for a "shoe-box" stage enclosure. ${ }^{40}$ The issue of empty stage versus occupied stage measurements has been discussed previously, particularly in the context of symphony orchestras and some methods proposed to use stage furniture to account for the effect of the orchestra. ${ }^{40,42}$ However, for a chamber orchestra playing predominantly standing, empty stage measurements are the most practical option. In the case of a standing chamber orchestra, the difference between the empty and occupied stage will presumably be less than for a full symphony orchestra. This suggests that the acoustic stage measurements undertaken in this study may be more representative of the true experience on stage than in previous studies that could not fully replicate the presence of a symphony orchestra on stage for their measurements. ${ }^{3,4,10}$

Importantly, the spatial distribution of early reflections on stage to musicians has now been observed in several studies, ${ }^{4,6,7,20}$ and warrants further investigation. In situ studies with musicians in halls can be used successfully to investigate these relationships, particularly if the following are achieved: (1) anonymous musician ID and instrument is recorded to allow for mixed-effects modeling, (2) questionnaires are completed as soon as possible after playing to avoid relying on auditory memory, and (3) acoustic conditions in the halls are matched to the playing experience for acoustic measurements. Last, while this study has focused on established omnidirectional parameters and some key spatial parameters defined at early times $(<100 \mathrm{~ms})$, some further investigations of spatial parameter at late times $(>100 \mathrm{~ms})$ could also be undertaken with this same dataset, but has been left for future work.

\section{CONCLUSIONS}

The subjective data presented here for chamber ensembles, and previous studies with symphony orchestras, ${ }^{4,10}$ indicate that musicians are assessing relevant aspects on stage in a holistic manner, and providing an OAI score which encompasses multiple aspects of acoustic experience on stage (cf. Kalkandjiev and Weinzier ${ }^{17}$ ). These OAI ratings were shown to be predicted better within linear models with spatially-defined parameters (both acoustic, and architectural idealizations thereof), compared to traditional omnidirectional parameters. In particular, the parameter $T H$, which assesses the ratio of reflections from above and from the horizontal plane appears promising, both as a standalone linear predictor of OAI, as well as a predictor within twoparameter interaction models with omnidirectional stage support parameters ( $S T_{\text {Late }}$ in particular). The parameter $H / D$, which grossly encapsulates the same idea as $T H$, 
provided the strongest linear model to predict OAI out of all the acoustic and architectural parameters. However, the latter should be recognized for what they are-simplifications of complex sound fields on stages-and their role must generally be to buttress the exploration of suitable acoustic parameters that characterize stage acoustics for musicians. In that regard, extensive studies of stage acoustics are few and far between (studies of chamber musicians are rarer), and some effort might be needed in the future to develop a critical mass regarding the relevance and application of spatially-selective acoustic parameters. However, recent findings from both laboratory and field studies of stage acoustics, including the current, have presented cogent reasons to suggest a shift from the more traditional omnidirectional parameters, to parameters that consider the spatial aspects of early sound fields on stage.

\section{ACKNOWLEDGMENTS}

The authors thank the musicians and management from ACO and Musica Viva Australia. L.P. was supported by an Australian Postgraduate Award, the Dr. Joan Woodberry Postgraduate Fellowship in Engineering and the Georgina Sweet Fellowship from the Australian Federation of Graduate Women. This research was supported by an Education Grant from the Australian Acoustical Society and by the Australian Research Council's Discovery Projects funding scheme (Grant No. DP120100484).

${ }^{1}$ A. H. Marshall, D. Gottlob, and H. Alrutz, "Acoustical conditions preferred for ensemble,” J. Acoust. Soc. Am. 64(5), 1437-1442 (1978).

${ }^{2}$ M. Barron, "The Gulbenkian Great Hall, Lisbon II: An acoustic study of a concert hall with variable stage," J. Sound. Vib. 59(4), 481-502 (1978).

${ }^{3}$ A. C. Gade, "Investigations of musicians' room acoustic conditions in concert halls ii: Field experiments and synthesis of results," Acta Acust. Acust. 69(6), 249-262 (1989).

${ }^{4}$ J. J. Dammerud, "Stage acoustics for symphony orchestras in concert halls," Ph.D. thesis, University of Bath, 2009, available at https://stageac. wordpress.com/ (Last viewed July 31, 2018).

${ }^{5}$ E. Van Den Braak and L. Van Luxemburg, "New (stage) parameter for conductor's acoustics?," in Proceedings of Acoustics '08, Paris (2008).

${ }^{6}$ A. Guthrie, "Stage acoustics for musicians: A multidimensional approach using 3D ambisonic technology," Ph.D. thesis, Rensselaer Polytechnic Institute, Troy, NY, 2014.

${ }^{7}$ L. Panton, D. Cabrera, D. Holloway, and L. Miranda, "Stage acoustics in eight Australian concert halls: Acoustic conditions in relation to subjective assessments by a touring chamber orchestra," Acoust. Australia 45(1), 25-39 (2017)

${ }^{8}$ A. C. Gade, "Practical aspects of room acoustic measurements on orchestra platform," in Proceedings of the International Congress on Acoustics, Beijing (1992).

${ }^{9}$ ISO 3382, "Acoustics-Measurement of room acoustic parameters-Part 1: Performance spaces" (International Organization for Standardization, Geneva, Switzerland, 2009).

${ }^{10} \mathrm{M}$. Cederlöf, "Podium acoustics for the symphony orchestra," Master Phil. thesis, Royal Institute of Technology, Stockholm, 2006

${ }^{11}$ A. C. Gade, "Acoustics of the orchestra platform from the musicians' point of view," in Proceedings of the Acoustics for Choir and Orchestra, Royal Swedish Academy of Music (1986).

${ }^{12}$ K. Ueno, T. Kanamori, and H. Tachibana, "Experimental study on stage acoustics for ensemble performance in chamber music," Acoust. Sci. Tech. 26(4), 345-352 (2005).

${ }^{13}$ W. Chiang, S. Chen, and C. Huang, "Subjective assessment of stage acoustics for solo and chamber music performances," Acta Acust. Acust. 89, 848-856 (2003).

${ }^{14}$ J. Sanders, "Suitability of New Zealand halls for chamber music," New Zealand Acoust. 15(1), 20-27 (2003).
${ }^{15}$ J. J. Dammerud, "Suggested data collection for assessing the acoustic condition on symphony orchestra stages" (2012), available at https://stageac. wordpress.com/ (Last viewed July 31, 2018).

${ }^{16}$ A. C. Gade, "Subjective and objective measures of relevance for the description of acoustics conditions on orchestra stages," in Proceedings of the International Symposium on Room Acoustics, Toronto (2013).

${ }^{17} \mathrm{Z}$. Kalkandjiev and S. Weinzierl, "An instrument for measuring perception of room acoustics from the perspective of musicians: The stage acoustic quality inventory (STAQI)," in Proceedings of DAGA, Müchen (2018).

${ }^{18} \mathrm{~K}$. Ueno and H. Tachibana, "Experimental study on the evaluation of stage acoustics by musicians using 6-channel sound simulation system," Acoust. Sci. Tech. 24(3), 130-138 (2003).

${ }^{19}$ D. Cabrera, R. McCarthy, J. Bassett, and D. Gilfillan, "The measurement of directional stage support in a drama theatre: Quantifying the acoustic effect of a set," Build. Acoust. 17(1), 1-14 (2010).

${ }^{20}$ D. S. Domínguez, "A study of musicians' room acoustic conditions," Master Phil. thesis, Technical University of Denmark, 2008.

${ }^{21}$ K. Ueno, K. Kato, and K. Kawai, "Effect of room acoustics on musicians' performance, Part I: Experimental investigation with a conceptual model," Acta Acust. Acust 96, 505-515 (2010).

${ }^{22}$ K. Kato, K. Ueno, and K. Kawai, "Effect of room acoustics on musicians' performance, Part II: Audio analysis of the variations in performed sound signals," Acta Acust. Acust 101, 743-759 (2015).

${ }^{23}$ A. Farina and L. Tronchin, "3D sound characterisation in theatres employing microphone arrays," Acta Acust. Acust. 99, 118-125 (2013).

${ }^{24}$ A. Dick and M. Vigeant, "A comparison of measured room acoustics metrics using a spherical microphone array and conventional methods," Appl. Acoust. 107, 34-45 (2016).

${ }^{25}$ R. Wilcox, Fundamentals of Modern Statistical Methods: Substantially Improving Power and Accuracy (Springer, New York, 2010).

${ }^{26}$ See supplementary material at https://doi.org/10.1121/1.5111748 for the original form of the questionnaire used in the survey, photographs of the concert halls measured and the Ambisonic weights used in spatially filtering.

${ }^{27}$ L. Panton, "Investigating auditorium acoustics from the perspective of musicians," Ph.D. thesis, University of Tasmania, 2017.

${ }^{28}$ D. Cabrera, D. Jimenez, and W. L. Martens, "Audio and acoustical response analysis environment (AARAE): A tool to support education and research in acoustics," in Proceedings of INTERNOISE 2014, Melbourne, Australia (2014).

${ }^{29}$ A. Parthy, N. Epain, A. van Schaik, and C. T. Jin, "Comparison of the measured and theoretical performance of a broadband circular microphone array," J. Acoust. Soc. Am. 130(6), 3827-3837 (2011).

${ }^{30} \mathrm{R}$ Core Team. "R: A Language and Environment for Statistical Computing," $R$ Foundation for Statistical Computing. Vienna, Austria, 2015.

${ }^{31} \mathrm{H}$. Wickham, tidyverse. R package version 1.2.1 (2017).

${ }^{32}$ I. Jolliffe, Principal Component Analysis (Wiley Online Library, 2002), pp. 78-103.

${ }^{33}$ J. L. Horn, "A rationale and test for the number of factors in factor analysis," Psychometrika 30, 179-185 (1965).

${ }^{34}$ B. P. O’Connor, paramap. R package version 1.4 (2017).

${ }^{35}$ M. Koller, "robustlmm: An R package for robust estimation of linear mixed-effects models," J. Stat. Software 75, 1-24 (2016).

${ }^{36}$ S. Nakagawa, P. C. D. Johnson, and S. Holger, "The coefficient of determination $R 2$ and intra-class correlation coefficient from generalized linear mixed-effects models revisited and expanded," J. R. Soc. Interface 14(134), 1-10 (2017).

${ }^{37}$ B. Efron, "Better bootstrap confidence intervals," J. Am. Stat. Assoc. 82, 171-185 (1987).

${ }^{38}$ M. Barron, Auditorium Acoustics and Architectural Design (Spon Press, London, 2010), $231 \mathrm{pp}$.

${ }^{39}$ A. C. Gade, "Acoustics for symphony orchestras; status after three decades of experimental research," in Proceedings of the International Symposium on Room Acoustics, Melbourne, Australia (2010).

${ }^{40}$ R. H. C. Wenmaekers, C. C. J. M. Hak, and M. C. J. Hornikx, "How orchestra members influence stage acoustic parameters on five different concert hall stages and orchestra pits," J. Acoust. Soc. Am. 140(6), 4437-4448 (2016).

${ }^{41}$ L. Panton, D. Holloway, and D. Cabrera, "Effect of a chamber orchestra on direct sound and early reflections for performers on stage: A boundary element method study," J. Acoust. Soc. Am. 141(4), 2461-2472 (2017).

${ }^{42}$ J. J. Dammerud and M. Barron, "Attenuation of direct sound and the contributions of early reflections within symphony orchestras," J. Acoust. Soc. Am. 128(4), 1755-1765 (2010). 